ARTICLE

\title{
Fire decline in dry tropical ecosystems enhances decadal land carbon sink
}

Yi Yin (10) 1,2凶 A. Anthony Bloom ${ }^{2 凶}$, John Worden (1) 2, Sassan Saatchi ${ }^{2}$, Yan Yang ${ }^{2}$, Mathew Williams (10) ${ }^{3,4}$, Junjie Liu ${ }^{1,2}$, Zhe Jiang (1D ${ }^{5}$, Helen Worden ${ }^{6}$, Kevin Bowman ${ }^{2}$, Christian Frankenberg (1) ${ }^{1,2}$ \& David Schimel ${ }^{2}$

The terrestrial carbon sink has significantly increased in the past decades, but the underlying mechanisms are still unclear. The current synthesis of process-based estimates of land and

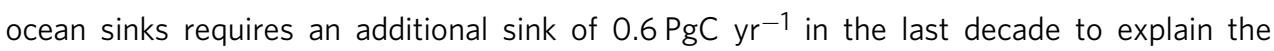
observed airborne fraction. A concurrent global fire decline was observed in association with tropical agriculture expansion and landscape fragmentation. Here we show that a decline of $0.2 \pm 0.1 \mathrm{PgC} \mathrm{yr}^{-1}$ in fire emissions during 2008-2014 relative to 2001-2007 also induced an additional carbon sink enhancement of $0.4 \pm 0.2 \mathrm{PgC}_{\mathrm{gr}}{ }^{-1}$ attributable to carbon cycle feedbacks, amounting to a combined sink increase comparable to the $0.6 \mathrm{PgC}_{\mathrm{yr}}{ }^{-1}$ budget imbalance. Our results suggest that the indirect effects of fire, in addition to the direct emissions, is an overlooked mechanism for explaining decadal-scale changes in the land carbon sink and highlight the importance of fire management in climate mitigation.

\footnotetext{
${ }^{1}$ Division of Geological and Planetary Sciences, California Institute of Technology, Pasadena, CA 91125, USA. ${ }^{2}$ Jet Propulsion Laboratory California Institute of Technology, Pasadena, CA 91101, USA. ${ }^{3}$ School of Geosciences, University of Edinburgh, Edinburgh EH9 3FF, UK. ${ }^{4}$ National Centre for Earth Observation, University of Edinburgh, Edinburgh EH9 3FF, UK. ${ }^{5}$ School of Earth and Space Sciences, University of Science and Technology of China, 230026 Hefei, Anhui, China. ${ }^{6}$ National Center for Atmospheric Research, Boulder, CO, USA. ${ }^{凶}$ email: yiyin@caltech.edu; abloom@jpl.nasa.gov
} 
F re is an important disturbance agent in the terrestrial ecosystem, particularly in the dry tropics, tightly coupled with vegetation, climate, biogeochemical cycles, and human activities $^{1-3}$. Climate plays a critical control on fire by regulating fuel load and conditions for fire ignition and spread ${ }^{4-7}$. However, human activities also affect fuel accumulation and fire risk and are responsible for most ignitions and all suppression efforts, thus they have a profound impact on the timing, frequency, extent, and intensity of fires $1,3,8$. With the rapid increase in human population and agricultural production in the last decades, many regions have transited from natural to human-dominated fire regimes ${ }^{9}$. A $25 \%$ decline in the global burned area (BA) from 1997 to 2015 has been observed combining multiple satellite data sets, with the most significant decreases in the savannas of Africa ${ }^{10}$. These declines are found to be correlated with agricultural expansion and landscape fragmentation ${ }^{10,11}$.

At the same time, a decrease in the fraction of anthropogenic $\mathrm{CO}_{2}$ emissions that remain in the atmosphere (airborne fraction, $-2.2 \%$ per year) has been observed for the period 2002-2014 ${ }^{12}$, despite continued increases in anthropogenic $\mathrm{CO}_{2}$ emissions ${ }^{13}$. However, processes explaining the terrestrial component of this increase-likely related to $\mathrm{CO}_{2}$ fertilization ${ }^{12,14}$, changing soil moisture and temperature regimes ${ }^{15}$, and land use and land cover change ${ }^{16}$-are still under debate. The Global Carbon Project (GCP) synthesizes observational and model-based flux estimates from multiple organizations and research groups around the world to report the Global Carbon Budget yearly ${ }^{13}$. Instead of treating the land sink as a residual term between the anthropogenic emissions and the atmospheric and ocean uptakes as historically being done, the most recent report provides explicit land sink estimates using an ensemble of land models that account for climate warming, $\mathrm{CO}_{2}$ fertilization, and land use change impacts, which result in a budget imbalance that requires an additional sink of $\sim 0.6 \mathrm{PgC}$ per year to explain the observed airborne fraction during the last decade ${ }^{13}$. Direct fire carbon emissions are often considered for global and regional carbon budgets $13,17,18$. In particular, deforestation fire and peatland burning are included in the land-use emission estimates ${ }^{13,19}$. However, impacts of wild fire decline on the subsequent ecosystem carbon cycling have not been well quantified, as prognostic fire models show large spreads in fire distribution and magnitude ${ }^{10}$ and fire modules in the land surface models included in the GCP synthesis are not explicitly guided by the observed BA changes ${ }^{13}$.

Under a dynamic equilibrium assumption, fire induces temporal changes in the carbon source and sink at yearly and decadal scale within one disturbance-recovery episode, but it has a negligible net effect on the long-term carbon budget because fireinduced carbon loss is eventually compensated by subsequent vegetation growth as the ecosystem recover toward equilibrium ${ }^{20,21}$. However, a shift in the fire regime could result in long-term carbon loss or gain if it leads to a different steady state of the carbon pools ${ }^{20,21}$. Here, we estimate changes in the land carbon sink attributable to the observed global BA decline over the last decade due to both direct (fuel combustion) and indirect (postfire ecosystem carbon cycle) impacts.

We use the CARbon DAta-MOdel fraMework (CARDA$\mathrm{MOM}^{22}$-constrained by atmospheric and land-surface $\mathrm{C}$ observations throughout 2001-2014-to estimate the impacts of fire decline on the terrestrial carbon cycle. The schematic of CARDAMOM carbon pools and associated observational constraints are depicted in Supplementary Fig. 1. Specifically, fire occurrences are constrained by satellite-derived $\mathrm{BA}$, and fire carbon emissions are derived as the product of BA, live biomass (leaf, labile, wood, and roots) and dead organic carbon stores (litter and soil organic carbon), as well as their associated combustion factors (percentages of fire loss relative to the total organic pool). In addition, biomass mortality rates are increased in the event of fire leading to a transfer of live biomass to dead organic carbon pools. The dynamics of the terrestrial carbon cycle are explicitly retrieved through a Bayesian model-data fusion estimation of key parameters for carbon cycle and initial states of carbon pools ${ }^{22}$. Assimilated datasets consist of fire carbon emissions inferred from atmospheric $\mathrm{CO}$ inversions assimilating MOPITT (Measurements Of Pollution In The Troposphere) ${ }^{23}$ and biome-specific $\mathrm{CO}$ to total carbon emission ratios ${ }^{24}$; satellitederived observations of leaf area index (LAI) ${ }^{25}$, Gross Primary Production (GPP) variability inferred from solar-induced fluorescence $(\mathrm{SIF})^{26}$, the spatial distribution of above-ground biomass ${ }^{27}$; inventory-derived global distribution of soil organic carbon (Harmonized World Soil Database, HWSD $^{28}$ ). The combustion factors and fire-induced mortality rates at each model grid cell are optimized given the CO-derived total carbon emission estimates. We first estimate fire carbon emissions from 2001 to 2014 using the observation-constrained CARDAMOM analysis, and then quantify the impacts of the observed BA decline on the other carbon cycle processes using sensitivity simulations. Our results suggest a decline of $0.2 \pm 0.1 \mathrm{PgC}$ per year in fire emissions between the two period 2008-2014 and 2001-2007, which also induced an additional carbon sink enhancement of $0.4 \pm 0.2 \mathrm{PgC}$ per year attributable to carbon cycle feedbacks, amounting to a combined sink increase comparable to the $0.6 \mathrm{PgC}$ per year budget imbalance.

\section{Results and discussion}

Observed declines in burned area and fire emissions. Global BA decreased by 34 Mha per year (-9\%) between 2001-2007 and 2008-2014 according to the Global Fire Emission Database (GFED4), and by 52 Mha per year $(-10 \%)$ according to GFED4s that accounts for small fires using thermal active fire data in addition to the BA detected from changes in surface reflectance retrieved from the MODIS (Moderate Resolution Imaging Spectroradiometer) instrument ${ }^{29,30}$. BA declines occurred mostly in savanna $(-10$ Mha per year, $-8 \%)$, woody savanna $(-9.6 \mathrm{Mha}$ per year, $-7 \%)$, and grassland $(-9.5 \mathrm{Mh}$ per year, $-21 \%)$ according to the MODIS land cover type ${ }^{31}$ (Fig. 1). The decrease of BA in the open shrubland is also large ( -3.3 Mha per year, $-15 \%)$ but has considerable interannual variations, whereas the decline in closed shrubland is significant but small in absolute magnitude $(-0.7$ Mha per year, $-23 \%)$. In contrast, BA changes

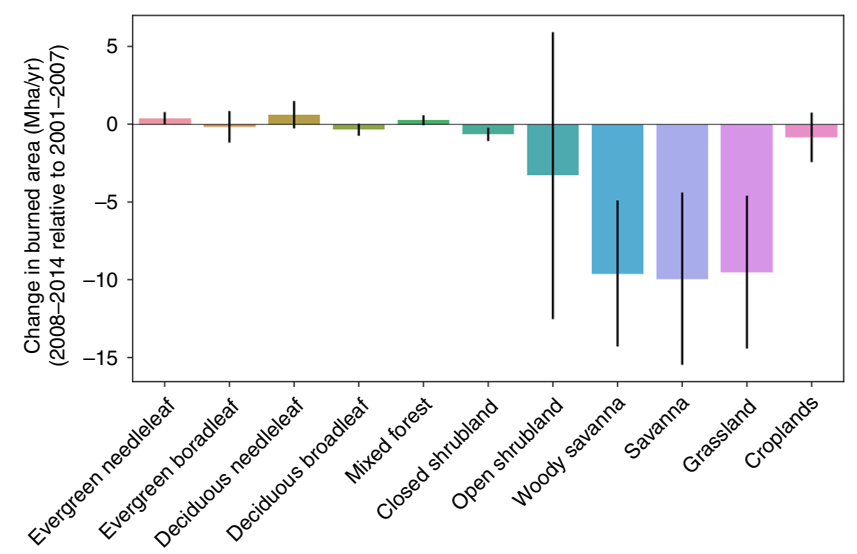

Fig. 1 Burned Area Change between 2008-2014 and 2001-2007. Burned Area (BA) estimates are from GFED4 dataset (synthesis of MODIS MCD64A1) and land cover type from MODIS MCD12Q1 product. The error bars show the uncertainty of individual year-to-year differences between the two period 2008-2014 and 2001-2007. 


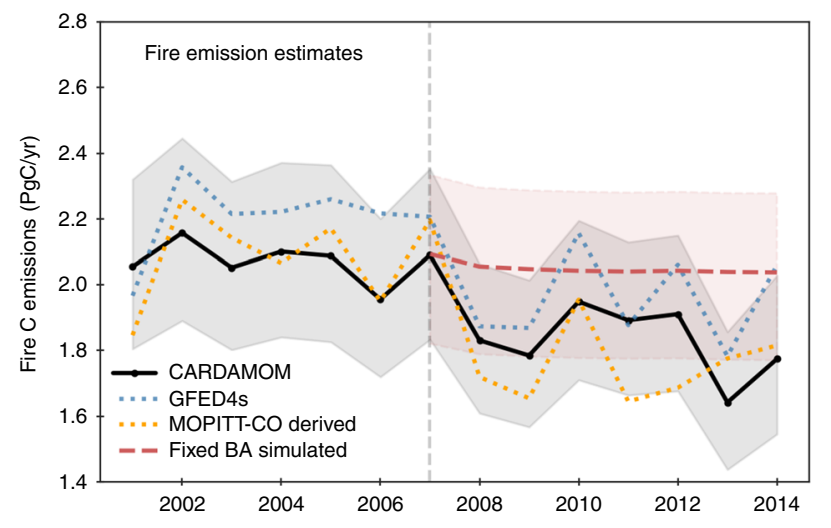

Fig. 2 Global fire carbon emissions estimates for 2001-2014. The solid black line represents fire carbon emissions estimated by the ensemble median of CARDAMOM, and the shading describes the first and third quartiles using a Monte-Carlo sampling of the parameters. The dotted blue line shows GFED4s bottom-up estimates, and the dotted orange line shows the estimates derived from MOPITT CO inversion and biome-specific emission ratios between $\mathrm{CO}$ and total carbon. The dashed red line represents simulated fire emissions using the average burned area during 2001-2007.

in forest-which have on average much lower fire frequenciesare relatively small in absolute magnitude and are associated with large interannual variations. The land cover types showing large BA declines have in general relatively short fire return times ranging from 1 year to a few years ${ }^{3}$, places showing significant decadal fire reductions are hence expected to experience changes in fire frequency and thus deviations from their typical fire disturbance-recovery trajectory. Additional BA dataset (ESA$\mathrm{CCI})^{32}$ that are also derived from MODIS instrument with a different algorithm shows a comparable spatial pattern as GFED4 and a decrease by 23 Mha per year $(-6 \%)$ between the two periods (Supplementary Fig. 2). Relatively smaller declines are found when small fires are not explicitly considered. Here, we use GFED4s as the reference version for further analysis as it is important to account for variations in small fires to fully capture fire dynamics ${ }^{29}$.

Fire carbon emissions estimated using CARDAMOM amount to $2.1 \pm 0.1 \mathrm{PgC}$ per year $\left(1 \mathrm{PgC}=1 \mathrm{e}^{15} \mathrm{~g}\right.$ Carbon $)$ across the globe for the period 2001-2007 and 1.8 $\pm 0.1 \mathrm{PgC}$ per year for the period 2008-2014 (Fig. 2, mean \pm standard deviation across different years based on CARDAMOM median estimates). An average decrease rate of $-1.5 \%$ per year is found over the period 2001-2014 $(p=0.01)$, with a faster decline of $-1.8 \%$ per year $(p=0.02)$ during the latter half from 2007 to 2014 compared to the non-significant decline during the first half from 2001 to 2007 $(-0.4 \%, p=0.5)$. This decadal decrease is supported by the GFED bottom-up approach and the MOPITT CO-inversion topdown estimates (Supplementary Fig. 3). Reductions in fire emission between the two episodes are mostly contributed by North Africa (i.e., the Sahel and sub-Sahelian regions, $-70 \pm 9$ TgC per year, $-16 \%)\left(1 \mathrm{TgC}=1 \mathrm{e}^{12} \mathrm{~g}\right.$ carbon), southern South America $\left(-60 \pm 20 \mathrm{TgC}^{-1},-30 \%\right)$, northern South America $(-53 \pm 9$ TgC per year, $-36 \%)$, Southeast Asia $(-55 \pm 22 \mathrm{TgC}$ per year, $-24 \%)$, Australia $(-23 \pm 4 \mathrm{TgC}$ per year, $-16 \%)$, and Europe $(-7.5 \pm 0.8$ TgC per year, $-30 \%$ ) (mean \pm standard deviations among the three approaches).

Impacts of fire decline on the subsequent carbon cycle. To quantify the impact of the observed BA decline between 2001-2007 and 2008-2014 on the carbon cycle, we performed a CARDAMOM control run with a constant 2008-2014 burned

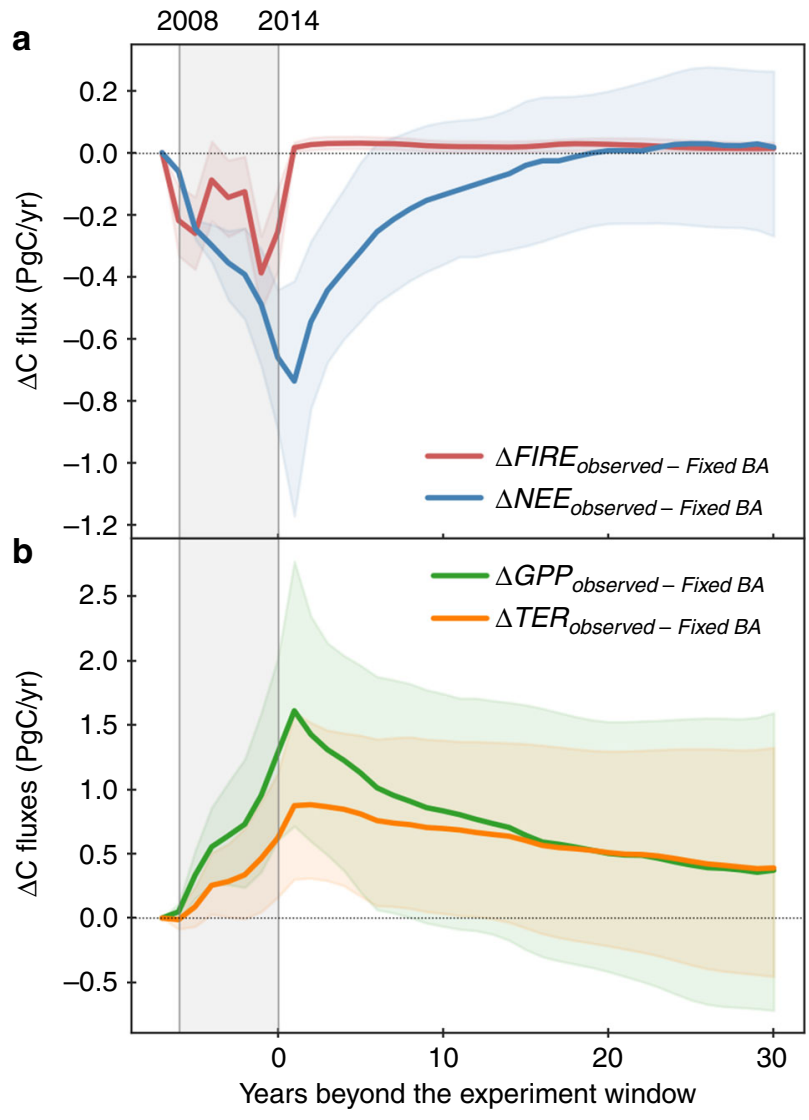

Fig. 3 Impacts of different BA scenarios on the global carbon cycle. a Relative differences in the simulated global fire carbon emissions ( $\triangle F I R E$ ) and net ecosystem exchange ( $\triangle \mathrm{NEE}$ ), and $\mathbf{b}$ Relative differences in the simulated global Gross Primary Productivity $(\triangle \mathrm{GPP})$ and Terrestrial Ecosystem Respiration ( $\triangle T E R$ ) between the Observed BA and the hypothetical BA scenarios-Fixed BA. The lines show the model median and the shadings show the range between 1st and 3nd quartile. Different BA scenarios are only applied within the experiment window (2008-2014) as marked by the grey shade, resultant differences beyond 2014 represent legacy effects of different BA during 2008-2014. Actual meteorological data is used from 2001 to 2014, and the same forcing data is repeatedly used for all scenarios beyond 2014 including the Observed BA.

area, using average 2001-2007 burned area values. All else being equal, the simulated differences between the observationretrieved carbon cycle states and fluxes (henceforth denoted as Observed BA) relative to the control run (henceforth denoted as Fixed BA) represent impacts of the Observed BA decline relative to the mean 2001-2007 fire levels. Fire emissions estimated using the Observed BA are $0.2 \pm 0.1 \mathrm{PgC}$ per year lower compared to the hypothetical case of Fixed BA averaged over 2008-2014 (Fig. 2, Fig. 3a). Beyond the 2008-2014 experiment window when all setups return to the same to evaluate the legacy effects of previous fire, differences in fire emissions between Observed BA and Fixed BA $(\triangle \mathrm{FIRE})$ reduced to $+0.03 \mathrm{PgC}$ per year averaged over 30 years. The slightly higher fire emissions associated with Observed BA result from larger fuel loads, because a lower 2008-2014 fire level had burned fewer organic matters and allowed more vegetation to regrow.

BA declines also result in a higher gross primary productivity relative to the control run $(\triangle \mathrm{GPP})$, as reduced fire occurrences allow more biomass to grow and hence an enhanced photosynthetic capacity (Fig. $3 \mathrm{~b}$ ). The increase in $\triangle \mathrm{GPP}$ due to BA decline results in an increase in the live biomass (Fig. 4), and an 
increase in turnover-induced dead carbon pool inputs; conversely, the BA decline results in a reduction in fire-induced mortality and hence a decline in dead carbon pool inputs. Due to the competing mortality processes the net dead organic carbon stock changes are more uncertain (Fig. 4). However, the overall increase in the terrestrial ecosystem respiration ( $\triangle \mathrm{TER}$ ) is a factor of two smaller than $\triangle$ GPP (Fig. 3b), thus resulting in a significant net ecosystem exchange $(\triangle \mathrm{NEE})$ reduction relative to the case of Fixed BA averaged over 2008-2014 $(\Delta \mathrm{NEE}=\Delta \mathrm{TER}-\Delta \mathrm{GPP}$, with positive values representing net fluxes from the land to the atmosphere). The indirect effect of fire decline on NEE is roughly twice the magnitude of the corresponding direct impacts on fire emissions.

Unlike $\triangle$ FIRE that show immediate responses to concurrent BA changes, $\triangle$ NEE increases gradually within the 2008-2014 experiment window as the cumulative differences in $\mathrm{BA}(\triangle \mathrm{BA})$ grow (Fig. 3a). The magnitude of $\triangle \mathrm{NEE}$ fluxes starts to decrease with a 1-year lag beyond the experiment window (i.e. response to $\triangle \mathrm{BA}$ of previous years), showing a near exponential decline of the legacy effects (Fig. 3a). The average $\triangle$ NEE during the first 5 years after BA perturbation is comparable to average effect within the experiment window $(-0.4 \pm 0.1 \mathrm{PgC}$ per year), but they reduce to $<50 \%$ and $10 \%$, respectively, for the 6-to-10-year and 11-to-20year windows (Fig. 3a). When accounting for fires, a neutral Net Biome Exchange (NBE = TER + FIRE-GPP) is reached within 18 years for the global average, more rapidly in South America and Africa (Supplementary Fig. 4), where a dominant contribution

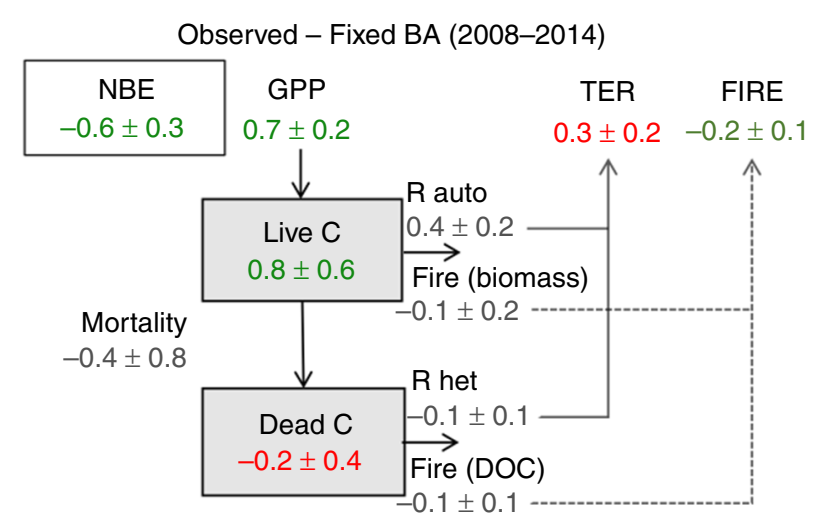

Fig. 4 Differences in the major carbon fluxes and pools between the two scenarios. The 2008-2014 average differences between the Observed BA and Fixed BA scenarios are shown (Units: PgC per year). Increases in the land sink is denoted in green and decreases in the land sink is denoted in red. NEE $=$ TER - GPP and NBE $=$ NEE + FIRE; negative NBE values represent net fluxes from the atmosphere to the land. Uncertainties are estimated by MCMC simulations. came from savanna ecosystem that are associated with a relatively short carbon residence time compared to forest ${ }^{21,22,33}$.

The GPP enhancement (and associated NEE reduction) is mostly attributable to the same regions exhibiting significant fire emission reductions (Fig. 5), namely the Sahel region in North Africa and dry sub-tropics in South America. In these dry tropical areas, positive trends are observed in the dry season enhanced vegetation index (EVI) and near-infrared reflectance of vegetation (NIRv) over the study period 2001-2014 (Supplementary Fig. 5), which is in agreement with our simulated responses in GPP to the burned area reduction. Besides, forest expansion and woody encroachment in the savannahs in Central and Western Africa are observed from space $^{34}$, consistent with our simulated responses to $\mathrm{BA}$ decline (Fig. 5). The regions in the dry tropics showing significant responses in simulated NEE are also generally in line with areas where satellite-based aboveground biomass estimates indicate net gains ${ }^{35}$. We note that the estimated increase in GPP due to reduced fire did not account for nutrient limitation $^{36}$ or grazing ${ }^{37}$, thus our estimation might be on the higher bound and future studies are needed to better understand the long-term effect to account for those factors along with vegetation successions ${ }^{38}$. Nevertheless, our simulated gains in the above-ground biomass after 7 years of fire reduction are in line with site-level observations that show substantial accumulation of woody biomass relative to 1-year fire frequency sites $\left(+220 \mathrm{gC} \mathrm{m}^{-2}\right)$ or relative to 3 -year fire frequency sites $\left(+130 \mathrm{gC} \mathrm{m}^{-2}\right)$ after long-term fire exclusion in a tropical savanna ecosystem ${ }^{39}$, as well as a $+160 \mathrm{gC} \mathrm{m}^{-2}$ increase in grass biomass compared to the 1-yr fire frequency site (Supplementary Fig. 6). This site-level comparison shows the estimated carbon enhancement are realistic at a process level. The simulated responses are also comparable with boreal fire studies showing a decrease of net primary production (NPP) by $60-260 \mathrm{gC} \mathrm{m}^{-2}$ per year after fire disturbance ${ }^{40}$.

Implications for the global carbon cycle. Accounting for our estimation of the fire decline impacts on the global carbon cycle relative to the case of Fixed BA at average 2001-2007 fire level, we could better explain the observed airborne fraction building on estimates of the other components from the GCP (see Methods). The adjusted airborne fraction estimates accounting for both direct and indirect effects of fire decline relative to the 2002-2007 mean significantly reduces the mean bias of the initial GCP estimates by $86 \%$ and the RMS by $53 \%$ reduction (Fig. 6 ). This improvement suggests that the enhancement of the land carbon sink due to fire reduction might have contributed to the global carbon budget with a magnitude comparable to the current estimates of the imbalance. It could have played a significant role in the recent terrestrial carbon sink increase, in addition to the widely recognized impacts of climate warming, $\mathrm{CO}_{2}$ fertilization,

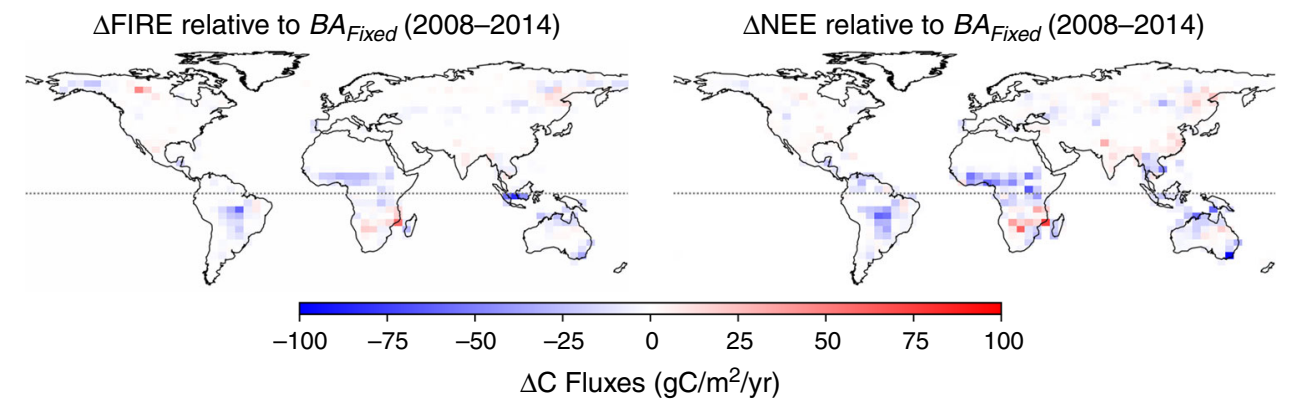

Fig. 5 Distribution of differences in fire and NEE fluxes between scenarios. Differences in the CARDAMOM simulated fire and NEE fluxes between the Observed BA and the Fixed BA scenarios averaged between 2008 and 2014. 


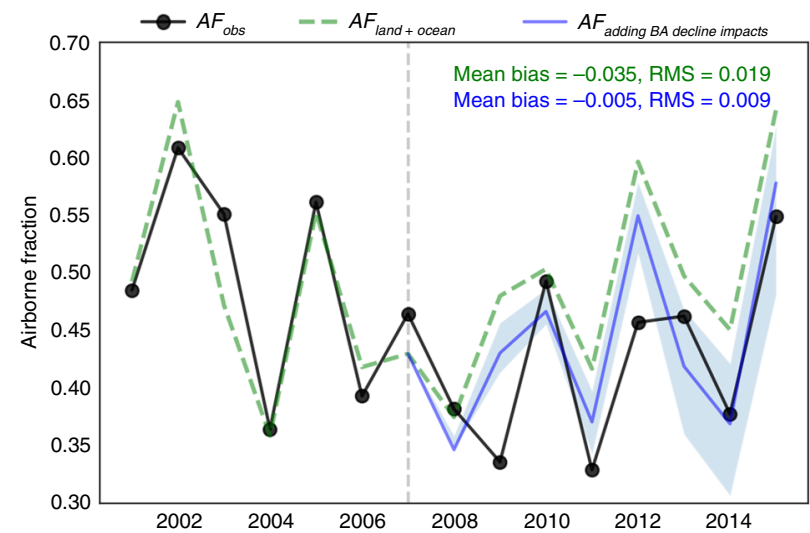

Fig. 6 Estimated impacts of fire decline on airborne fraction. The impacts of fire decline between 2008-2014 and 2001-2007 are evaluated here. Emissions from Fossil fuel $\left(E_{\mathrm{FF}}\right)$ and from land use change $\left(E_{\mathrm{LUC}}\right)$, atmospheric $\mathrm{CO}_{2}$ growth rate $\left(G_{A T M}\right)$, and process-based sink estimates for ocean ( $\mathrm{S}_{\text {OCEAN }}$ ) and land ( $\mathrm{S}_{\text {LAND }}$ ) are derived from GCP 2018 estimates to determine the airborne fraction (each component shown in Supplementary Fig. 10. $A F_{\text {obs }}=G_{A T M} /\left(E_{F F}+E_{L U C}\right)$, showing the observed $G_{A T M}$ relative to the total emissions from $E_{\mathrm{FF}}$ and $E_{\mathrm{LUC}} ; \mathrm{AF}_{\text {land }+ \text { ocean }}=1-\left(\mathrm{S}_{\mathrm{OCEAN}}+\mathrm{S}_{\mathrm{LAND}}\right) /$ $\left(E_{\mathrm{FF}}+E_{\mathrm{LUC}}\right)$, representing the portion of $\mathrm{AF}$ variations that can be explained by current process-based estimates of land and ocean sinks; $A F_{+B A}$ Decline $=1$ $-\left(S_{\text {OCEAN }}+S_{\text {LAND }}-\Delta\right.$ FIRE $\left.-\Delta N E E\right) /\left(E_{F F}+E_{\text {LUC }}\right)$, representing the adjusted $\mathrm{AF}$ by adding for our estimates of $\mathrm{BA}$ decline impacts relative to the mean 2001-2007 BA. Note that the adaptations to 2015 are only due to the legacy effect of the period 2008-2014.

and land use change as addressed in $\mathrm{GCP}^{13}$, as well as other processes that are not explicitly accounted for. While land use change emissions do account for fire emissions, in particular, those related to deforestation and cropland conversion, and typical subsequent recovery ${ }^{13,16,19}$, the mechanisms we highlight here include the explicit representation of feedbacks between reduced fires and increased leaf area, potential limitations induced by additional growth potential through water availability, and subsequent impacts on heterotrophic respiration. Further investigation into the relative impacts of these processes is critical to improve understanding and reduce uncertainty on the response of ecosystems to reduced fire activity. We also note that although CARDAMOM results explicitly represent the role of parametric uncertainty on the reported increases in GPP and $\mathrm{NEE}$, it is necessary for future efforts to investigate the role of model structural uncertainties.

Here, we focus on the impacts of fire decline between the two periods, 2001-2007 and 2008-2014, hence the legacy effects of past fire dynamics (those before 2007) are not explicitly addressed - even though their impacts are implicitly included in the carbon cycle parameters inferred from satellite data using CARDAMOM. Their impacts would have been identical for our sensitivity simulations, thus not impacting the results deduced from differences between the BA scenarios. Trace gas mixing ratios in ice cores and charcoal data indicates a much higher biomass burning emissions over the past millennium compared to the contemporary level ${ }^{41,42}$. African fires, contributing to around $60 \%$ of the global fire carbon emissions, have declined since the $1950 \mathrm{~s}^{9}$. A recent model study showed that increasing population densities and cropland area have decreased global BA since the 1930 s and result in a significant reduction in global fire emissions (0.13 PgC per year for the period 1960-2009) ${ }^{43}$, but the indirect impacts on NEE in addition to fire emissions are not analyzed explicitly. The much larger magnitude of the indirect, lagged NBE effect, as we show here, due to fire decline relative to its direct impacts on fire emission implies an even larger contribution of fire declines to the global land sink increase during the past decades. Missing this important mechanism in explaining the global land carbon sink increase over the past decades could lead to an overestimation of other processes, such as $\mathrm{CO}_{2}$ fertilization $^{44,45}$, and thus significant biases in future carbonclimate feedback projections. The indirect effect of the global burned area decline is an overlooked mechanism that may explain some of the land carbon sink increase in recent decades. This mechanism is likely effective at a decadal time scale, if a lower fire level is sustained, till the ecosystem reaches a steady state but unlikely to continue indefinitely as climate projections suggest increased fire risk $^{8}$ and extreme droughts associated with El Niño events could result in non-linear fire responses ${ }^{5,18}$. Therefore, fire management is an important strategy for terrestrial carbon storage and thus climate mitigation.

\section{Methods}

Satellite-derived burned area and bottom-up fire emissions. We use satellitederived burned area (BA) from the Global Fire Emissions Database (GFED) $)^{30,46}$ and the ESA-CCI product ${ }^{32}$ at a spatial resolution of $0.25^{\circ}$ and a temporal resolution of monthly. We include two versions from GFED: GFED4 based on changes in the surface reflectance, and GFED4s that, in addition to the GFED4 BA, account for small fires using active fire information to extend the detection limit ${ }^{47}$. We focus on the period from 2001 to 2014, during which the BA are consistently retrieved from MODIS and the atmospheric CO retrievals are available from MOPITT. GFED4s BA is used as the reference version in this study, while the rests are used for sensitivity tests. GFED also provides gridded monthly fire emissions from multiple fire tracers using a bottom-up approach ${ }^{2,46}$. CO emission estimates from GFED3 are used as the prior for fire emissions in our atmospheric inversion described below.

Atmospheric top-down fire emissions estimates. Complementary to the ground fire features derived from satellite, trace gases emitted from biomass burning could provide valuable top-down constraints to fire emission estimates, in particular $\mathrm{CO}$, because it has a relatively simple source structure (mainly from fossil fuel and biomass burning with relatively small spatial colocations) and a lifetime of a few weeks allowing the track of the transport from its source regions ${ }^{48}$. Using a twostep inversion system that combines a sequential Kalman filter to optimize boundary conditions and a variational assimilation system to optimize fluxes, we assimilate MOPITT CO retrievals (version $6^{49}$ ) with GeosChem to optimize monthly $\mathrm{CO}$ emissions from fire and fossil fuel, and additional sources from hydrocarbon oxidation (details are documented in Jiang et al. ${ }^{23}$ ). The version of GeosChem we use here has a spatial resolution of $4^{\circ} \times 5^{\circ}$ and a vertical resolution of 47 levels $^{23}$. We convert MOPITT-derived fire CO emission into fire carbon emission using biome-specific ratios of emission factors between $\mathrm{CO}$ and the total carbon following GFED4. Uncertainties in the CO inversion and the ratio between emission factors are propagated into the uncertainty of CO-derived fire carbon emission estimates following the method in Worden et al. ${ }^{50}$. The derived fire carbon emissions and associated uncertainties are used to constraint CARDAMOM fire emissions described below.

CARDAMOM: data constrained carbon cycle model. CARDAMOM represents six carbon pools (foliar, labile, wood, fine roots, litter, and soil carbon) and one plant-available water pool in each model grid, and simulates the processes controlling their dynamic evolutions in time ${ }^{22,51}$ (Supplementary Fig. 1). The forcing data consist of monthly meteorology reanalysis (ERA- interim) from European Centre for Medium-Range Weather Forecasts (ECMWF) and BA from GFED4s. The total carbon input is represented by the gross primary production (GPP), which is a function of meteorology and the photosynthetic capacity depending on foliar carbon pool; autotrophic respiration (Ra) is a function of GPP and temperature; the net primary production (NPP) is then allocated into the four live biomass pools. Plant mortality is expressed by the turnover time of each carbon pool and organic matters moved into litter or soil carbon pools are subject to further decomposition as a function of temperature and moisture (Rh). Fire is introduced by prescribed BA, causing the combustion of live biomass and dead organic matters and an increase in mortality rate. Key model parameters controlling the carbon cycle (photosynthesis, phenology, allocation, and turnover rates) and fire-related processes (combustion factors for foliar, structural, litter and soil $\mathrm{C}$ pools, as well as a fire resilience factor) are optimized within each grid at a $4^{\circ} \times 5^{\circ}$ resolution, the same resolution as the MOPITT-CO inversion, using a Metropolis-Hastings Markov Chain Monte Carlo Approach ${ }^{22}$. The parameters are not distinguished by plant functional types (please see details in Bloom et al. ${ }^{22}$; Bloom et al. ${ }^{51}$ ). 
Deducing fire decline impacts on the airborne fraction. We convert our estimated $\triangle$ FIRE and $\triangle$ NEE fluxes between the Observed BA and the Fixed BA scenarios into equivalent changes in the airborne fraction (AF). The other budget terms are adopted from the most recent GCP global carbon budget ${ }^{13}$. For each year, GCP synthesize $\mathrm{CO}_{2}$ emissions from fossil fuel and industry using energy statistics $\left(E_{\mathrm{FF}}\right)$, land-use change emissions based on bookkeeping models $\left(E_{\mathrm{LUC}}\right)$, and ocean $\left(S_{\text {OCEAN }}\right)$ and terrestrial carbon sinks $\left(S_{\text {LAND }}\right)$ based on the state-of-theart process models (Supplementary Fig. 7). The atmospheric growth rate is directly determined by the atmospheric $\mathrm{CO}_{2}$ observations $\left(G_{\mathrm{ATM}}\right)$. Ideally, if every component is accurately estimated: $E_{\mathrm{FF}}+E_{\mathrm{LUC}}=G_{\mathrm{ATM}}+S_{\mathrm{OCEAN}}+S_{\mathrm{LAND}}$, the observed airborne fraction, $\mathrm{AF}_{\mathrm{obs}}=G_{\mathrm{ATM}} /\left(E_{\mathrm{FF}}+E_{\mathrm{LUC}}\right)$, would match perfectly the process-explained variations, $\mathrm{AF}_{\text {land }+ \text { ocean }}=1-\left(S_{\mathrm{OCEAN}}+S_{\mathrm{LAND}}\right) /\left(E_{\mathrm{FF}}+E_{\mathrm{LUC}}\right)$. However, due to imperfect understanding of the contemporary carbon cycle and model representation, there is a mismatch. We thus include our estimated fire impacts on $\triangle \mathrm{FIRE}$ and $\triangle \mathrm{NEE}$ to evaluate the updated attribution, $\mathrm{AF}_{+\mathrm{BA} \text { Decline }}=$ $1-\left(S_{\text {OCEAN }}+S_{\text {LAND }}-\Delta \mathrm{FIRE}-\Delta \mathrm{NEE}\right) /\left(E_{\mathrm{FF}}+E_{\mathrm{LUC}}\right)$.

\section{Data availability}

All data and CARDAMOM code are available upon request from the corresponding authors.

Received: 6 March 2020; Accepted: 1 April 2020;

Published online: 20 April 2020

\section{References}

1. Bowman, D. M. J. S. et al. Fire in the Earth System. Science 324, 481-484 (2009).

2. van der Werf, G. R. et al. Global fire emissions and the contribution of deforestation, savanna, forest, agricultural, and peat fires (1997-2009). Atmos. Chem. Phys. 10, 11707-11735 (2010).

3. Archibald, S., Lehmann, C. E. R., Gomez-Dans, J. L. \& Bradstock, R. A. Defining pyromes and global syndromes of fire regimes. Proc. Natl Acad. Sci. USA 110, 6442-6447 (2013).

4. Marlon, J. R. et al. Global biomass burning: a synthesis and review of Holocene paleofire records and their controls. Quat. Sci. Rev. 65, 5-25 (2013).

5. Chen, Y. et al. A pan-tropical cascade of fire driven by El Niño/Southern Oscillation. Nat. Clim. Change 7, 906-911 (2017).

6. van der Werf, G. R. et al. Climate regulation of fire emissions and deforestation in equatorial Asia. Proc. Natl Acad. Sci. USA 105, 20350-20355 (2008).

7. van der Werf, G. R., Randerson, J. T., Giglio, L., Gobron, N. \& Dolman, A. J. Climate controls on the variability of fires in the tropics and subtropics. Global Biogeochem. Cycles 22, GB3028 (2008).

8. Pechony, O. \& Shindell, D. T. Driving forces of global wildriers over the past millennium and the forthcoming century. Proc. Natl Acad. Sci. USA 107, 19167-19170 (2010).

9. van Marle, M. J. E. et al. Historic global biomass burning emissions for CMIP6 (BB4CMIP) based on merging satellite observations with proxies and fire models (1750-2015). Geosci. Model Dev. 10, 3329-3357 (2017).

10. Andela, N. et al. A human-driven decline in global burned area. Science. 356. 1356-1362 (2017).

11. Zubkova, M., Boschetti, L., Abatzoglou, J. T. \& Giglio, L. Changes in fire activity in Africa from 2002 to 2016 and their potential drivers. Geophys. Res. Lett. https://doi.org/10.1029/2019GL083469 (2019).

12. Keenan, T. F. et al. Recent pause in the growth rate of atmospheric $\mathrm{CO} 2$ due to enhanced terrestrial carbon uptake. Nat. Commun. 7, 13428 (2016).

13. Le Quéré, C. et al. Global carbon budget 2017. Earth Syst. Sci. Data 10, 405-448 (2018).

14. Schimel, D., Stephens, B. B. \& Fisher, J. B. Effect of increasing $\mathrm{CO} 2$ on the terrestrial carbon cycle. Proc. Natl Acad. Sci. USA 112, 436-441 (2015).

15. Ballantyne, A. et al. Accelerating net terrestrial carbon uptake during the warming hiatus due to reduced respiration. Nat. Clim. Change 7, 148-152 (2017).

16. Piao, S. et al. Lower land-use emissions responsible for increased net land carbon sink during the slow warming period. Nat. Geosci. https://doi.org/ 10.1038/s41561-018-0204-7 (2018)

17. Liu, J. et al. Contrasting carbon cycle responses of the tropical continents to the 2015-2016 El Niño. Science 358, eaam5690 (2017).

18. Yin, Y. et al. Variability of fire carbon emissions in Equatorial Asia and its non-linear sensitivity to El Niño. Geophys. Res. Lett., https://doi.org/10.1002/ 2016GL070971 (2016).

19. Houghton, R. A. et al. Carbon emissions from land use and land-cover change. Biogeosciences 9, 5125-5142 (2012).
20. Kashian, D. M., Romme, W. H., Tinker, D. B., Turner, M. G. \& Ryan, M. G Carbon storage on landscapes with stand-replacing fires. Bioscience 56, 598-606 (2006).

21. Luo, Y. \& Weng, E. Dynamic disequilibrium of the terrestrial carbon cycle under global change. Trends Ecol. Evol. 26, 96-104 (2011).

22. Bloom, A. A., Exbrayat, J.-F., van der Velde, I. R., Feng, L. \& Williams, M. The decadal state of the terrestrial carbon cycle: Global retrievals of terrestrial carbon allocation, pools, and residence times. Proc. Natl Acad. Sci. USA. https://doi.org/10.1073/pnas.1515160113 (2016).

23. Jiang, Z. et al. A 15-year record of $\mathrm{CO}$ emissions constrained by MOPITT CO observations. Atmos. Chem. Phys. 17, 4565-4583 (2017).

24. Akagi, S. K. et al. Emission factors for open and domestic biomass burning for use in atmospheric models. Atmos. Chem. Phys. 11, 4039-4072 (2011).

25. Myneni, R., Knyazikhin, Y., DAAC. \& Park, T. MOD15A2 MODIS/Terra Leaf Area Index/FPAR 8-Day L4 Global 1 km SIN Grid. (Boston University. MODAPS SIPS - NASA, 2015) https://doi.org/10.5067/MODIS/ MOD15A2.006.

26. Parazoo, N. C. et al. Terrestrial gross primary production inferred from satellite fluorescence and vegetation models. Glob. Change Biol. 20, 3103-3121 (2014).

27. Saatchi, S. S. et al. Benchmark map of forest carbon stocks in tropical regions across three continents. Proc. Natl Acad. Sci. USA 108, 9899-9904 (2011).

28. Hiederer, R. \& Köchy, M. Global soil organic carbon estimates and the harmonized world soil database. EUR 79, 25225 (2011).

29. Randerson, J. T., Chen, Y., van der Werf, G. R., Rogers, B. M. \& Morton, D. C Global burned area and biomass burning emissions from small fires. $J$. Geophys. Res. 117, G04012 (2012).

30. Giglio, L., Randerson, J. T. \& van der Werf, G. R. Analysis of daily, monthly, and annual burned area using the fourth-generation global fire emissions database (GFED4). J. Geophys. Res. Biogeosci. 118, 317-328 (2013).

31. Friedl, M. A. et al. MODIS Collection 5 global land cover: algorithm refinements and characterization of new datasets. Remote Sens. Environ. 114 168-182 (2010).

32. Chuvieco, E. et al. Generation and analysis of a new global burned area product based on MODIS $250 \mathrm{~m}$ reflectance bands and thermal anomalies. Earth Syst. Sci. Data 10, 2015-2031 (2018).

33. Carvalhais, N. et al. Global covariation of carbon turnover times with climate in terrestrial ecosystems. Nature 514, 213-217 (2014).

34. Song, X.-P. et al. Global land change from 1982 to 2016. Nature 560, 639-643 (2018).

35. Baccini, A. et al. Tropical forests are a net carbon source based on aboveground measurements of gain and loss. Science 358, 230-234 (2017).

36. Pellegrini, A. F. A. et al. Fire frequency drives decadal changes in soil carbon and nitrogen and ecosystem productivity. Nature 553, 194-198 (2018).

37. McSherry, M. E. \& Ritchie, M. E. Effects of grazing on grassland soil carbon: a global review. Glob. Change Biol. 19, 1347-1357 (2013).

38. Bond, W. J. \& Keeley, J. Fire as a global 'herbivore': the ecology and evolution of flammable ecosystems. Trends Ecol. Evol. 20, 387-394 (2005).

39. Pellegrini, A. F. A., Hedin, L. O., Staver, A. C. \& Govender, N. Fire alters ecosystem carbon and nutrients but not plant nutrient stoichiometry or composition in tropical savanna. Ecology 96, 1275-1285 (2015).

40. Hicke, J. A. et al. Postfire response of North American boreal forest net primary productivity analyzed with satellite observations. Glob. Change Biol. 9, 1145-1157 (2003).

41. Wang, Z., Chappellaz, J., Park, K. \& Mak, J. E. Large variations in southern hemisphere biomass burning during the last 650 Years. Science 330, 1663-1666 (2010).

42. van der Werf, G. R., Peters, W., van Leeuwen, T. T. \& Giglio, L. What could have caused pre-industrial biomass burning emissions to exceed current rates? Clim 9, 289-306 (2013).

43. Arora, V. K. \& Melton, J. R. Reduction in global area burned and wildfire emissions since 1930s enhances carbon uptake by land. Nat. Commun. 9, 1326 (2018).

44. Kolby Smith, W. et al. Large divergence of satellite and Earth system model estimates of global terrestrial CO2 fertilization. Nat. Clim. Change 6, 306-310 (2016).

45. Fernández-Martínez, M. et al. Global trends in carbon sinks and their relationships with CO2 and temperature. Nat. Clim. Change 9, 73-79 (2019).

46. van der Werf, G. R. et al. Global fire emissions estimates during 1997-2016. Earth Syst. Sci. Data 9, 697-720 (2017)

47. Giglio, L., Loboda, T., Roy, D. P., Quayle, B. \& Justice, C. O. An active-fire based burned area mapping algorithm for the MODIS sensor. Remote Sens. Environ. 113, 408-420 (2009).

48. Yin, Y. et al. Decadal trends in global CO emissions as seen by MOPITT. Atmos. Chem. Phys. 15, 13433-13451 (2015). 
49. Deeter, M. N. et al. The MOPITT Version 6 product: algorithm enhancements and validation. Atmos. Meas. Tech. 7, 3623-3632 (2014).

50. Worden, J. R. et al. Reduced biomass burning emissions reconcile conflicting estimates of the post-2006 atmospheric methane budget. Nat. Commun. 8, 2227 (2017)

51. Bloom, A. A. \& Williams, M. Constraining ecosystem carbon dynamics in a data-limited world: integrating ecological "common sense" in a model-data fusion framework. Biogeosciences 12, 1299-1315 (2015).

\section{Acknowledgements}

Funding for this study was provided through a NASA ROSES Carbon Cycle and Ecosystems grant (\#13-CARBON13_2-0071) and NASA Earth Science grant

(NNH16ZDA001N-IDS). Part of this research was carried out at the Jet Propulsion Laboratory, California Institute of Technology, under a contract with the National Aeronautics and Space Administration.

\section{Author contributions}

J.W., A.A.B., Y.Yin, and D.S. designed the study; Y.Yin and A.A.B. performed the analysis; S.S. and Y.Yang provided information about tropical ecosystem responses to fire disturbance; H.W. and Z.J. provided information on fire $\mathrm{CO}$ emissions; M.W., J.L., K.B. and C.F. contributed to the interpretation of the results. Y.Yin wrote the paper with inputs from all authors.

\section{Competing interests}

The authors declare no competing interests.

\section{Additional information}

Supplementary information is available for this paper at https://doi.org/10.1038/s41467020-15852-2.

Correspondence and requests for materials should be addressed to Y.Y. or A.A.B.

Peer review information Nature Communications thanks Richard Houghton and other, anonymous, reviewers for their contributions to the peer review of this work. Peer review reports are available.

Reprints and permission information is available at http://www.nature.com/reprints

Publisher's note Springer Nature remains neutral with regard to jurisdictional claims in published maps and institutional affiliations.

\begin{abstract}
(c) (1)
Open Access This article is licensed under a Creative Commons Attribution 4.0 International License, which permits use, sharing, adaptation, distribution and reproduction in any medium or format, as long as you give appropriate credit to the original author(s) and the source, provide a link to the Creative Commons license, and indicate if changes were made. The images or other third party material in this article are included in the article's Creative Commons license, unless indicated otherwise in a credit line to the material. If material is not included in the article's Creative Commons license and your intended use is not permitted by statutory regulation or exceeds the permitted use, you will need to obtain permission directly from the copyright holder. To view a copy of this license, visit http://creativecommons.org/ licenses/by/4.0/.
\end{abstract}

(C) The Author(s) 2020 